\title{
CARACTERIZAÇÃO FÍSICO-QUÍMICA E AVALIAÇÃO ENERGÉTICA DE GELÉIA ELA- BORADA EM DIFERENTES TIPOS DE TACHOS COM POLPA E SUCO DE ACEROLA ${ }^{\mathbf{1}}$ PRISCILLA KÁRIM CAETANO²; ÉRICA REGINA DAIUTO ${ }^{3} \&$ ROGÉRIO LOPES VIEITES ${ }^{4}$
}

RESUMO: O objetivo deste trabalho foi realizar a caracterização físico-química. O rendimento e a avaliação energética de geléias de acerola elaboradas com polpa e suco do fruto em diferentes tipos de tachos (alumínio, cobre e inox). As análises realizadas foram: rendimento médio, $\mathrm{pH}$, acidez titulável, sólidos solúveis ('Brix), sólidos totais, vitamina C, açúcar redutor, açúcar redutor total, caloria e cor. O rendimento da geléia foi maior para o suco (59\%) em relação à polpa (55\%). As geléias elaboradas em tachos de alumínio apresentaram maiores rendimentos em relação aos outros. $\mathrm{O}$ pH a acidez e o ${ }^{\circ}$ Brix para geléia de polpa foram respectivamente de 3,48, $0,51 \%$ e 67,11 e para suco $3,47,0,47 \%$ e 67,85 . Sobre o teor de açucares para a geléia, as médias variaram de 24,94 a 21,69\% e a de suco 30,84 a 24,77\%. A concentração de vitamina $C$ reduziu-se à metade após o cozimento, sendo o valor encontrado para suco e a polpa de acerola $1054 \mathrm{mg} / 100 \mathrm{ml}$. Para a geléia de polpa variou de 664,79 a 610,69 a de suco de 599,25 a 428,63 $\mathrm{mg} / 100 \mathrm{ml}$. As formulações com suco da fruta alcançaram maiores valores de luminosidade. Já a cor amarela foi mais acentuada nas formulações de polpa. Em relação ao tacho, os melhores resultados foram para as geléias produzidas em tacho de alumínio. Para a avaliação energética os valores não diferiram entre si, e esses resultados estão de acordo com a literatura.

Palavras-chave: Malphigia emarginata, vitamina C, processamento

\footnotetext{
${ }^{1}$ Parte da dissertação de mestrado do $1^{\text {o }}$ autor intitulada: Processamento Tecnológico e Avaliação Energética de geléia de acerola

${ }^{2}$ Aluna do Programa de Pós-Graduação em Agronomia (Energia na Agricultura), FCA/UNESP - Fazenda Experimental Lageado. Rua José Barbosa de Barros, 1780. CEP: 18610-307. Botucatu/SP/Brasil. Caixa Postal 237. Telefone:+ 55 (14) 3811-7273. E-mail: prikarim@gmail.com

${ }^{3}$ Aluna de Pós-Doutorado em Horticultura, FCA/UNESP - Fazenda Experimental Lageado. Rua José Barbosa de Barros, 1780. CEP: 18610-307. Botucatu/SP/Brasil. Caixa Postal 237. Telefone:+ 55 (14) 3811-7273.

E-mail: erdaiuto@uol.com.br

${ }^{4}$ Orientador e docente do Departamento de Gestão e Tecnologia Agroindustrial, FCA/UNESP - Fazenda Experimental Lageado. Rua José Barbosa de Barros, 1780. CEP: 18610-307. Botucatu/SP/Brasil. Caixa Postal 237.

Telefone:+ 55 (14) 3811-7172. E-mail: vieites@fca.unesp.br
} 


\section{PHYSICAL CHEMICAL CHARACTERIZATION AND ENERGY EVALUATION OF JELLY PREPARED IN DIFFERENT TYPES OF POTS WITH PULP AND ACEROLA JUICE}

SUMMARY: The objective of this work was the physiochemical characterization, yield and energy evaluation of acerola jelly elaborated with pulp and juice of the fruit in different pots (aluminum, copper and inox). The evaluated analyses were medium yield, $p H$, titratable acidity, soluble solids ( $\left.{ }^{\circ} \mathrm{Brix}\right)$, total solids, vitamin $C$, sugar reducer, sugar total reducer and color. The yield of the jelly was higher for the juice (59\%) than the pulp (55\%). The jellies elaborated in aluminum pots presented higher yield than the other ones. The $p H$, acidity and ${ }^{\circ}$ Brix for pulp jelly were respectively 3,48, 0,51\% and 67,11 and for juice 3,47, $0,47 \%$ and 67,85 . The pulp jelly sugar content was $22,03 \%$ and for the juice $30,84 \%$. The vitamin concentration $C$ was reduced in half after the cooking, being the value found for acerola juice and pulp 1054 $\mathrm{mg} / 100 \mathrm{ml}$, for the jelly pulp it varied from 664,79 to 610,69 and for the one of juice 599,25 to 428,63 $\mathrm{mg} / 100 \mathrm{ml}$.The formulations with juice of the fruit reached higher values of brightness. Already the yellow color was more accentuated in the pulp formulations. In relation to the pots the best results were the jellies produced in aluminum pots. To evaluate energy values did not differentiate between them, but the results are consistent with the literature.

Keywords: Malphigia emarginata, vitamin C, processing

\section{INTRODUÇÃO}

A aceroleira, também conhecida como cerejeira das Antilhas é uma planta rústica de porte arbustivo. O Brasil ocupa o primeiro lugar na produção e exportação da acerola, em razão da existência de condições favoráveis de clima e solo em grande área do país. Trata-se de uma fruta altamente requisitada no mercado mundial devido ao seu valor nutricional, com destaque para o teor de vitamina C (JUNQUEIRA, 2002).

As frutas tropicais são altamente perecíveis, deteriorando-se em poucos dias. Este fato dificulta sua comercialização, na forma in natura, a grandes distâncias. Estima-se que nas áreas tropicais e subtropicais as perdas pós-colheita das frutas e hortaliças variam entre 15 a 50\%, principalmente por manuseio e preservação inadequados (CHITARRA;CHITARRA, 2005). A acerola é uma destas frutas tropicais. Aliado ao seu valor nutricional, torna-se importante o desenvolvimento de produtos com esta matéria prima. A transformação de frutas em produtos possibilita absorver grande parte da colheita, favorecendo o consumo 
de frutas durante o ano todo e a redução do desperdício de alimentos. Além do consumo in natura a acerola pode ser usada na fabricação de bebidas, sorvetes, doces, iogurtes e geléias.

As geléias podem ser consideradas como o segundo produto em importância comercial para a indústria de conservas de frutas brasileiras (SOLER, 1991). A literatura relata pouca pesquisa sobre formulação, preparo e características organolépticas da geléia de acerola. Mélo et al. (1999) realizaram estudo sobre formulação, avaliação físico-química e sensorial de geléia mista de pitanga e acerola e Negrete (2001) avaliou um processo de elaboração a vácuo para a geléia de acerola e também a vida de prateleira.

O modo de preparo para obtenção da geléia é uma etapa importante, pois, os alimentos permanecem por variados tempos de residência em recipientes industriais e utensílios domésticos que podem alterar o valor nutricional dos mesmos (QUINTAES et al., 2004). O cobre, mineral usado para confeccionar vários utensílios domésticos, dentre eles, os tachos e as panelas usadas nas cozinhas tradicionais para a fabricação de doces artesanais, realça a cor de todos os tipos de doces de frutas, mas principalmente os doces de frutas verdes como o figo, limão, mamão, dentre outros. A panela de alumínio é a menos indicada pelos profissionais de saúde, pois há estudos relatando a passagem de resíduos do metal deste utensílio para a comida. Ela altera a cor dos doces escurecendo-os. Já as panelas de aço inox não trazem nenhum prejuízo à saúde, pois, a liga de que é formada, composta de ferro, cromo e níquel, é bastante segura. Elas têm a capacidade de distribuírem o calor de forma uniforme como as de cobre, mas não são indicadas para cozinhar doce, pois o aço inox faz com que os doces percam a cor original das frutas. São recomendados para acondicionamento dos doces após o cozimento (SBRT, 2009).

Outro fator importante a ser determinado no alimento é seu valor energético. Esta é uma medida usada, frequentemente, para expressar o calor ou valor energético do alimento e da atividade física. Através do método de calorimetria direta, descobriu-se que cada alimento libera um determinado calor ao ser queimado. O calor liberado pela queima é enunciado como o valor energético do alimento (McARDLE,1992). De acordo com a Agência Nacional de Vigilância Sanitária - ANVISA (BRASIL, 2003), a rotulagem nutricional é toda descrição destinada a informar ao consumidor sobre as propriedades nutricionais de um alimento. Ela é obrigatória e deve compreender a declaração de valor energético e de teor de nutrientes (carboidratos, proteínas, gorduras totais, entre outros). Essas informações devem ser apresentadas claramente nos rótulos de produtos alimentícios para facilitar sua livre circulação, evitar obstáculos técnicos ao comércio e, principalmente, atuar em benefício do consumidor.

O objetivo deste trabalho foi caracterizar a geléia de acerola elaborada em diferentes tipos de tachos, com polpa e suco do fruto, quanto ao rendimento de produção, avaliação energética e análises físicoquímicas. 


\section{MATERIAL E MÉTODOS}

\subsection{Material}

As acerolas maduras foram colhidas manualmente num pomar comercial onde se cultiva a variedade Olivier implantado em 1997, no município de Junqueirópolis, região chamada de Nova Alta Paulista, Estado de São Paulo. Foi realizada uma pré-limpeza para retirar os galhos, folhas, pedúnculos, frutas deterioradas e insetos. As frutas foram selecionadas de acordo com a maturação e posteriormente lavadas três vezes em água corrente e sanitizadas em solução clorada (1\%) durante 20 minutos. Depois de selecionadas, foram extraídos o suco integral e a polpa. As matérias primas utilizadas na fabricação da geléia foram polpa de acerola, suco integral de acerola, açúcar comercial (cristal) e pectina comercial. Já os equipamentos utilizados foram despolpadora, prensa e tachos de alumínio, cobre e inox.

\subsection{Extração do suco integral e polpa de acerola}

Após a lavagem e seleção, foi extraída a polpa através da despolpadora descontinua com peneira de malha $0,5 \mathrm{~mm}$. A despolpadora foi carregada com $5 \mathrm{~kg}$ de fruta in natura e mantida em funcionamento por 10 minutos. A extração do suco foi através da prensa manual com o uso de tecido sintético de malha fina do tipo "voil", utilizando 1,5 kg de fruta por batelada, com pressão de 2 toneladas (indicada em manômetro). Depois de extraídos, o suco e a polpa foram acondicionados em garrafas plásticas.

\subsection{Rendimento da matéria prima}

Foi calculado através da relação entre a massa extraída de polpa ou suco e a massa de fruta. O cálculo do rendimento realizou-se na seguinte equação:

$$
R=\frac{\text { Mpolpa / suco }}{\text { Mfruta }} * 100
$$

Onde:

$\mathrm{R}=$ Rendimento

$\mathrm{m}$ polpa/suco = massa de suco e polpa extraída

$\mathrm{m}$ fruta $=$ massa de acerola pesada 


\subsection{Avaliação energética}

As análises energéticas foram determinadas por bomba calorimétrica (SILVA,1990), calculadas da seguinte forma:

$$
P C S=\left(\frac{K+M_{H 20}}{m_{c}}\right) * C *(T f-T i)
$$

Onde:

$\mathrm{K}$ = constante do calorímetro, determinada previamente utilizando-se o ácido benzoico com PCS de $6318 \mathrm{cal} / \mathrm{g}$;

$M_{H 20}=$ massa de água pré-estabelecida em gramas (2500g);

$m_{c}=$ massa do combustível (g);

$\mathrm{C}=$ calor especifico da água $\left(1,0 \mathrm{cal} / \mathrm{g}^{\mathrm{o}} \mathrm{c}\right)$;

$\mathrm{Ti}$ = temperatura inicial obtida pelo termômetro;

$\mathrm{Tf}$ = temperatura final obtida após a combustão.

\subsection{Características físico-químicas da matéria prima}

O suco e a polpa de acerola foram homogeneizados e analisados quanto aos teores de sólidos totais (gravimetria), sólidos solúveis (cálculo), sólidos insolúveis em água (gravimetria), sólidos solúveis ( ${ }^{0}$ Brix por refratômetro), pH (potenciômetro), acidez titulável (titulometria), relação sólidos solúveis/acidez titulável (ratio), cinzas (gravimetria) e umidade de acordo com BRASIL (2005); açúcar redutor-AR e açúcar total-AT (licor de Fehling), conforme COPERSUCAR (1980) e vitamina C pelo Método de Tillmans modificado conforme MAPA (2008).

\subsection{Processamento da geléia}

Elaborou-se geléia tipo Extra, sendo as formulações polpa/açúcar (1:1) e suco/açúcar (1:1), ambas com 1\% de pectina, e cada formulação elaborada em tachos de alumínio, cobre e inox (Tabela 1). 
Tabela 1 - Tipo de matéria prima e tipo de tacho utilizado na fabricação de geléia de acerola.

\begin{tabular}{cll}
\hline Tratamentos & $\begin{array}{c}\text { Matéria prima e } \\
\text { proporção }\end{array}$ & \multicolumn{1}{c}{ Tachos } \\
\hline T1 & polpa/açúcar (1:1) & Alumínio \\
T2 & polpa/açúcar (1:1) & Cobre \\
T3 & polpa/açúcar (1:1) & Inox \\
& suco/açúcar (1:1) & Alumínio \\
T4 & suco/açúcar (1:1) & Cobre \\
T5 & suco/açúcar (1:1) & Inox \\
T6 & & \\
\hline
\end{tabular}

A cocção foi feita em tachos abertos, com agitação manual continua. A polpa foi aquecida até aproximadamente $70^{\circ} \mathrm{C}$ e logo adicionado o açúcar. Quando foi adicionado o açúcar ocorreu à formação de espuma, a qual foi retirada com colher espumadeira no final da cocção (SOLER, 1991). Próximo ao ponto final de cozimento com temperatura acima de $100{ }^{\circ} \mathrm{C}$ foi adicionado a pectina e deixou-se chegar a concentração final de sólidos solúveis de 67,5³rix, medido em refratômetro. A temperatura final foi de 103,6 ${ }^{\circ} \mathrm{C}$ e o tempo para a realização da produção da geléia variou de 45 a 50 minutos. Após esta etapa, envasouse a geléia a quente em embalagens de vidro com capacidade para 250 g, previamente esterilizadas a 121 ${ }^{\circ} \mathrm{C} / 15$ min e fechadas com tampa de metal e invertidas. As geléias foram resfriadas em água até aproximadamente $40^{\circ} \mathrm{C}$ e armazenado a temperatura ambiente.

\subsection{Rendimento das geléias}

Foi determinado pela relação entre a massa de geléia e a massa de polpa, suco e açúcar sendo calculado pela equação:

$$
R=\frac{\text { Mgeléia }}{\text { Msuco } / \text { polpa }+ \text { açúcar }} * 100
$$

Onde:

$\mathrm{R}=$ Rendimento

$\mathrm{m}$ geléia $=$ massa de geléia obtida 
suco/polpa + açúcar = massa de suco e polpa obtido pela extração, mais o açúcar adicionado na formulação para a fabricação da geléia.

\subsection{Características físico-químicas da geléia}

As geléias produzidas foram analisadas quanto ao $\mathrm{pH}$ (potenciômetro), acidez titulável (titulometria), sólidos solúveis ( ${ }^{\circ}$ Brix por refratômetro), sólidos totais (gravimetria) e umidade conforme BRASIL (2005); as determinações de açúcar redutor-AR e açúcar redutor total-ART (licor de Fehling) foram de conforme COPERSUCAR (1980) e vitamina C pelo Método de Tillmans modificado conforme MAPA (2008).

\subsection{Cor}

As amostras de geléias foram medidas em colorímetro da marca Konica Minolta (Chroma meter, CR 400/410), faixa de comprimento de onda de 380 a $780 \mathrm{~nm}$. Foram realizadas as leituras de refletância com ângulo de observação de $2^{\circ}$ e selecionado o iluminante C. A cor foi expressa pelo sistema de coordenadas retangulares $\mathrm{L}^{*} \mathrm{a} * \mathrm{~b} *$ conforme a CIE (Comission Internatinale de E'clairage), onde L* expressa em porcentagem valores de luminosidade $(0 \%=$ negro e $100 \%=$ branco $)$, $a^{*}$ representa as cores vermelha $(+)$ ou verde (-) e b* as cores amarela (+) ou azul (-). Nos resultados são apresentados os valores de L a* e b*.

\subsection{Análise dos dados}

O delineamento experimental utilizado foi inteiramente casualizado. Para a comparação entre as médias foi utilizado o teste de Tukey ao nível de 5\% de probabilidade de acordo com as recomendações de Gomes (2000).

\section{RESULTADOS E DISCUSSÃO}

A polpa apresentou rendimento de 73,68\% e o suco $68,76 \%$ no processo de extração realizado na despolpadora e na prensa manual. O resultado do rendimento da polpa está coerente aos valores citados para acerola por Brunini et al. (2004), Asenjo (1980) e por Scholtz e Stenzel (1996). Segundo Semensato e 
Pereira (2000), calculando o rendimento do suco houve variação de 40,83 a 65,63\%. O alto rendimento de ambos deveu-se a alta umidade do fruto e a alta porcentagem que a polpa representa no peso total do fruto.

Na caracterização química da fruta (Tabela 2) observou-se que para todas as análises realizadas não houve efeito significativo, exceto a vitamina C.

Os resultados apresentados para sólidos solúveis ( $\left.{ }^{\circ} \mathrm{Brix}\right), \mathrm{pH}$ e acidez estão de acordo com Gomes et al. (2000), onde o pH variou de 3,07 a 3,82 e o teor de sólidos solúveis de 5,25 a 8,58. Gonzaga Neto et al. (1994) verificaram que o pH do suco e da polpa de acerola, depende do completo estádio de maturação da fruta encontrando valores de acidez de 0,79 a $1,90 \%$.

Os valores de açúcares redutores e açúcares redutores totais foram semelhantes, demonstrando que a polpa e o suco não acumulam sacarose e seus açúcares são provavelmente a glicose e fructose. Conforme Chitarra e Chitarra (2005), o teor de açúcares constitui de $65 \%$ a $85 \%$ do teor de sólidos solúveis ( ${ }^{\circ}$ Brix), estando de acordo com os dados apresentados na Tabela 2.

Tabela 2 - Caracterização química e físico-química de polpa e suco de acerola extraída da prensa e despolpadora.

\begin{tabular}{ccc}
\hline Análises & \multicolumn{2}{c}{ matéria-prima } \\
\hline & Suco & Polpa \\
\hline${ }^{\mathbf{0} B r i x}$ & $7,61 \mathrm{~b} \pm 0,04$ & $7,93 \mathrm{a} \pm 0,03$ \\
Acidez Titulável(\%) & $0,84 \mathrm{a} \pm 0,00$ & $0,94 \mathrm{~b} \pm 0,02$ \\
Ratio & $0,57 \mathrm{a} \pm 0,00$ & $0,53 \mathrm{~b} \pm 0,01$ \\
pH & $3,47 \mathrm{a} \pm 0,01$ & $3,44 \mathrm{~b} \pm 0,02$ \\
Açúcar redutor (\% de glicose) & $5,17 \mathrm{a} \pm 0,07$ & $5,26 \mathrm{a} \pm 0,18$ \\
Açúcar redutor total (\% de sacarose) & $4,82 \mathrm{~b} \pm 2,64$ & $5,14 \mathrm{a} \pm 0,02$ \\
Umidade (\%) & $92,49 \mathrm{a} \pm 0,28$ & $91,17 \mathrm{~b} \pm 0,53$ \\
Cinzas (\%) & $0,31 \mathrm{~b} \pm 0,00$ & $0,42 \mathrm{a} \pm 0,01$ \\
Sólidos insolúveis (\%) & $0,67 \mathrm{~b} \pm 1,14$ & $4,23 \mathrm{a} \pm 0,11$ \\
Vitamina C (mg/100ml) & $1054 \mathrm{a} \pm 23,79$ & $1054 \mathrm{a} \pm 8,99$
\end{tabular}

Médias seguidas das mesmas letras minúsculas na linha não diferem estatisticamente pelo teste Tukey a 5\% de probabilidade, seguidas do desvio padrão.

Para o teor de sólidos insolúveis, a polpa apresentou resultado significativo devido à grande quantidade de sólidos em suspensão que atravessou a peneira de malha $0,5 \mathrm{~mm}$, enquanto que da prensa foi extraído suco com menor teor de sólidos insolúveis. A despolpadora desintegra as frutas, produzindo de- 
tritos celulares. Estas partículas passam livremente pela malha da peneira, permanecendo na polpa. Já na prensagem, as frutas são esmagadas, mas não trituradas, permanecendo praticamente íntegras, sem gerar os fragmentos celulares. Além disso, o tecido sintético "voil” usado para acondicionar as acerolas durante a prensagem, tinha malha de aproximadamente $0,1 \mathrm{~mm}$ que reteve as partículas maiores geradas no processo. Para os teores de cinzas, os resultados estão de acordo com Chaves et al. (2004), onde a fração encontrada foi de $0,43 \%$.

Os resultados de vitamina C foram iguais para o suco e polpa, $1054 \mathrm{mg} / 100 \mathrm{ml}$, sendo os valores concordantes com Paiva et al. (2002). Para Simão (1971), quanto mais ácida a variedade da acerola se apresentar, mais altos serão os teores de vitamina C. Este fato foi constatado por Lima et al. (2002), que caracterizando acerolas maduras encontraram teores de ácido ascórbico variando de 1.066,66 a 1.845,79 mg 100 mL-1 de polpa, e frutos menos ácidos com menores teores de vitamina C.

Em relação ao rendimento da geléia, independente do tipo de matéria prima não houve influência para maior rendimento. Observou-se que a geléia produzida com suco obteve maior rendimento comparado à polpa, cujos valores variaram de 59,9 e 55\% e ambos feitos em tacho de alumínio (Tabela 3).

Tabela 3 - Rendimento das formulações de geléias em função do tipo de tacho e matéria prima

\begin{tabular}{ccc}
\hline $\begin{array}{c}\text { Matéria } \\
\text { prima }\end{array}$ & Tipos de tachos & $\begin{array}{c}\text { Rendimento } \\
\text { (\%) }\end{array}$ \\
\hline \multirow{2}{*}{ Polpa 50-50 } & Alumínio & 55 \\
& Inox & 54,5 \\
& Cobre & 51,9 \\
\hline \multirow{2}{*}{ Suco 50/50 } & Alumínio & 59,9 \\
& Inox & 59 \\
& Cobre & 57,5 \\
\hline
\end{tabular}

Sabe-se que a acidez e o pH das geléias devem ser controlados. A acidez total não deve exceder a 0,8\%, e o mínimo indicado é de 0,3\%. Quanto ao pH, sugere-se um pH máximo de 3,4, sendo que, abaixo de 3,0 ocorre uma tendência à sinérese (JACKIX, 1988). As geléias (Tabela 4) apresentaram um valor acima do recomendado, no entanto, não foi observado prejuízo na formação do gel. Negrete (2001) comprovou que o aumento do $\mathrm{pH}$ na fabricação de geléia de acerola não prejudicou a qualidade da geléia, pois teve boa aceitação na análise sensorial.

Semensato e Pereira (2000) confirmaram que a acerola é uma fruta ácida, demonstrando a possibilidade de sua utilização industrial para a fabricação de geléias e doces, sem a adição de ácidos no 
processamento.

Os teores sólidos solúveis ( ${ }^{\circ}$ Brix), expressos na Tabela 4, estão de acordo com Soler (1991), onde a concentração de açúcar deve ser em torno de $67,5{ }^{\circ}$ Brix. O ponto final da geléia acima deste valor, resulta na formação de cristais e abaixo em uma geléia muito mole. Notou-se que após a remoção da água existente na geléia através do método de secagem em estufa a $105^{\circ} \mathrm{C}$, esta apresentou em sua estrutura valores médios de 69,73 a 67,89 ${ }^{\circ}$ Brix, de sólidos totais para a geléia feita com polpa com uma umidade de 30,27 a 32,11\% e para a geléia feita com suco de 70,20 a 68,37 sólidos totais e a umidade 29,80 a 31,63\%. Os resultados encontrados estão de acordo com Miguel et al.(2008), que em geléia de melão encontrou resultados para umidade de $29,78 \%$.

Tabela 4 - Caracterização química e físico-química e avaliação energética de geléia de acerola produzida com polpa e suco de acerola.

\begin{tabular}{ccccccc}
\hline Análises & \multicolumn{7}{c}{ Tratamentos } \\
\cline { 2 - 7 } & T1 & T2 & T3 & T4 & T5 & T6 \\
\hline pH & $3,48 \mathrm{a}$ & $3,43 \mathrm{~b}$ & $3,48 \mathrm{a}$ & $3,47 \mathrm{a}$ & $3,42 \mathrm{~b}$ & $3,46 \mathrm{a}$ \\
& $\pm 0,00$ & $\pm 0,01$ & $\pm 0,01$ & $\pm 0,00$ & $\pm 0,01$ & $\pm 0,01$ \\
\hline \multirow{2}{*}{ Acidez Titulável(\%) } & $0,51 \mathrm{~b}$ & $0,54 \mathrm{a}$ & $0,55 \mathrm{a}$ & $0,36 \mathrm{c}$ & $0,47 \mathrm{~b}$ & $0,49 \mathrm{~b}$ \\
& $\pm 0,00$ & $\pm 0,01$ & $\pm 0,00$ & $\pm 0,00$ & $\pm 0,00$ & $\pm 0,00$ \\
\hline \multirow{2}{*}{ Sólidos Solúveis ('Brix) } & $67,11 \mathrm{~b}$ & $67,76 \mathrm{a}$ & $67,83 \mathrm{a}$ & $67,44 \mathrm{~b}$ & $67,85 \mathrm{a}$ & $67,96 \mathrm{a}$ \\
& $\pm 0,27$ & $\pm 0,25$ & $\pm 0,15$ & $\pm 0,13$ & $\pm 0,18$ & $\pm 0,12$ \\
\hline \multirow{2}{*}{ Sólidos totais (\%) } & $67,89 \mathrm{~b}$ & $68,65 \mathrm{~b}$ & $69,73 \mathrm{a}$ & $68,37 \mathrm{~b}$ & $69,58 \mathrm{a}$ & $70,20 \mathrm{a}$ \\
& $\pm 0,09$ & $\pm 0,09$ & $\pm 0,12$ & $\pm 0,08$ & $\pm 0,01$ & $\pm 0,04$ \\
\hline Açúcar redutor (\% de & $22,03 \mathrm{~b}$ & $24,94 \mathrm{~b}$ & $21,69 \mathrm{~b}$ & $30,84 \mathrm{a}$ & $24,88 \mathrm{~b}$ & $24,77 \mathrm{~b}$ \\
glicose) & $\pm 0,12$ & $\pm 0,34$ & $\pm 0,07$ & $\pm 1,40$ & $\pm 0,29$ & $\pm 0,18$ \\
\hline Açúcar redutor total & $60,34 \mathrm{a}$ & $56,13 \mathrm{~b}$ & $54,37 \mathrm{~b}$ & $62,22 \mathrm{a}$ & $61,74 \mathrm{a}$ & $62,30 \mathrm{a}$ \\
(\% de sacarose) & & & & & & \\
& $\pm 0,22$ & $\pm 0,90$ & $\pm 3,14$ & $\pm 0,86$ & $\pm 0,23$ & $\pm 0,68$ \\
& & & & & & \\
\hline Valor energético & $296,98 \mathrm{a}$ & $296,83 \mathrm{a}$ & $296,75 \mathrm{a}$ & $296,42 \mathrm{a}$ & $296,41 \mathrm{a}$ & $296,64 \mathrm{a}$ \\
(Kcal) & $\pm 0,72$ & $\pm 0,62$ & $\pm 0,65$ & $\pm 0,40$ & $\pm 0,53$ & $\pm 0,56$ \\
\hline (mitamina C & $664,79 \mathrm{a}$ & $610,69 \mathrm{~b}$ & $660,63 \mathrm{a}$ & $428,63 \mathrm{c}$ & $579,48 \mathrm{~b}$ & $599,25 \mathrm{~b}$ \\
& $\pm 3,12$ & $\pm 4,76$ & $\pm 6,49$ & $\pm 7,85$ & $\pm 17,74$ & $\pm 23,56$ \\
\hline
\end{tabular}

Médias seguidas das mesmas letras minúsculas na linha não diferem estatisticamente pelo teste Tukey a 5\% de probabilidade, seguidas do desvio padrão 
A concentração de acido ascórbico encontrado foi de 599,25 a 428,63 mg para a geléia feita com suco e 664,79 a 660,63 mg para a de polpa em 100 g de geléia. Verificou-se após o cozimento para obtenção da geléia que o teor de ácido ascórbico é reduzido à metade em relação à concentração encontrada no suco e na polpa de acerola, que foi de $1054 \mathrm{mg} / 100 \mathrm{ml}$.

Negrete (2001) analisando geléias de acerola observou que a concentração de ácido ascórbico após o processamento foi entre 456,32 mg e 587,45 mg em cada 100g de geléia, concluindo assim que os resultados na Tabela 4 assemelham-se aos citados neste trabalho.

Mustard (1946) processou geléia de acerola e determinou a concentração de ácido ascórbico através do método colorimétrico. As médias das análises foram de 683 a 509 mg de ácido ascórbico para $100 \mathrm{~g}$ de geléia. Neste trabalho a autora relata a quantidade de ácido ascórbico e cita que três colheres de chá poderiam suprir a IDR (ingestão diária recomendada) de vitamina C.

Segundo Desrosier (1963) durante o processamento e cozimento, a sacarose, na presença de ácido, sofre hidrólise na qual, açúcares redutores, glicose e frutose, são formados. $\mathrm{O}$ autor ainda acrescenta que o produto de conversão é conhecido como açúcar invertido e a taxa de inversão depende da temperatura, do tempo de aquecimento e do pH da solução (meio).

Na elaboração de geléias é desejável a presença de açúcares redutores, tendo em vista que estes atuam conferindo aspecto mais brilhante, evitando e, em alguns casos, retardando a cristalização da sacarose, impedindo a exsudação e por fim, reduzindo o grau de doçura das geléias (JACKIX, 1988).

Para os açucares redutores, os valores médios variaram de 24,94 a 22,03\% para geléia de polpa e 30,84 a 24,77\% de glicose para a de suco. Moreira et al. (2005), encontraram valores compreendidos entre 24,77 e 61,36\% de açucares redutores em geléias comerciais de morango. Assis et al. (2007), estudaram o processamento de estabilidade da geléia de caju e encontraram concentração de 24,29\% de açucares redutores, com estas citações, verificou-se que os resultados assemelham aos apresentados na Tabela 3.

Já para os açucares redutores totais, as concentrações encontradas para a geléias de suco variaram de 62,22 a $61,74 \%$ e para polpa foi de 60,34 a 54,37\% de sacarose. Os valores encontrados estão de acordo com Moreira et al. (2005), que encontraram valores compreendidos de 55,71 e 78,51\% e Assis et al. (2007), 68,47\% para açúcares totais.

Quanto ao valor energético foi observado que os valores não diferenciaram entre si, mostrando assim que não existe diferença entre as formas de extração e nem ao tipo de tacho utilizado. Os resultados estão de acordo com Negrete (2001), que encontrou valores semelhantes ao citado neste trabalho.

Em relação ao tipo de tacho utilizado, todos os resultados estão de acordo com a literatura, mas observou-se que o T1 apresentou uma quantidade maior de Vitamina C. As geléias feitas em tachos de alumínio (T1 e T4) renderam mais do que as feitas nos outros tachos. Analisando o pH, foi observado que as geléias feitas em tachos de cobre (T2 e T5) apresentaram valores mais próximos ao que é exigido pela 
legislação. No entanto, os dados analisados não diferiram estatisticamente entre si.

Para o atributo cor, foi avaliada a luminosidade, intensidade de vermelho ( $\left.\mathrm{a}^{*}\right)$ e intensidade de amarelo (b*). A Figura 1 apresenta as medias para os tratamentos realizados.
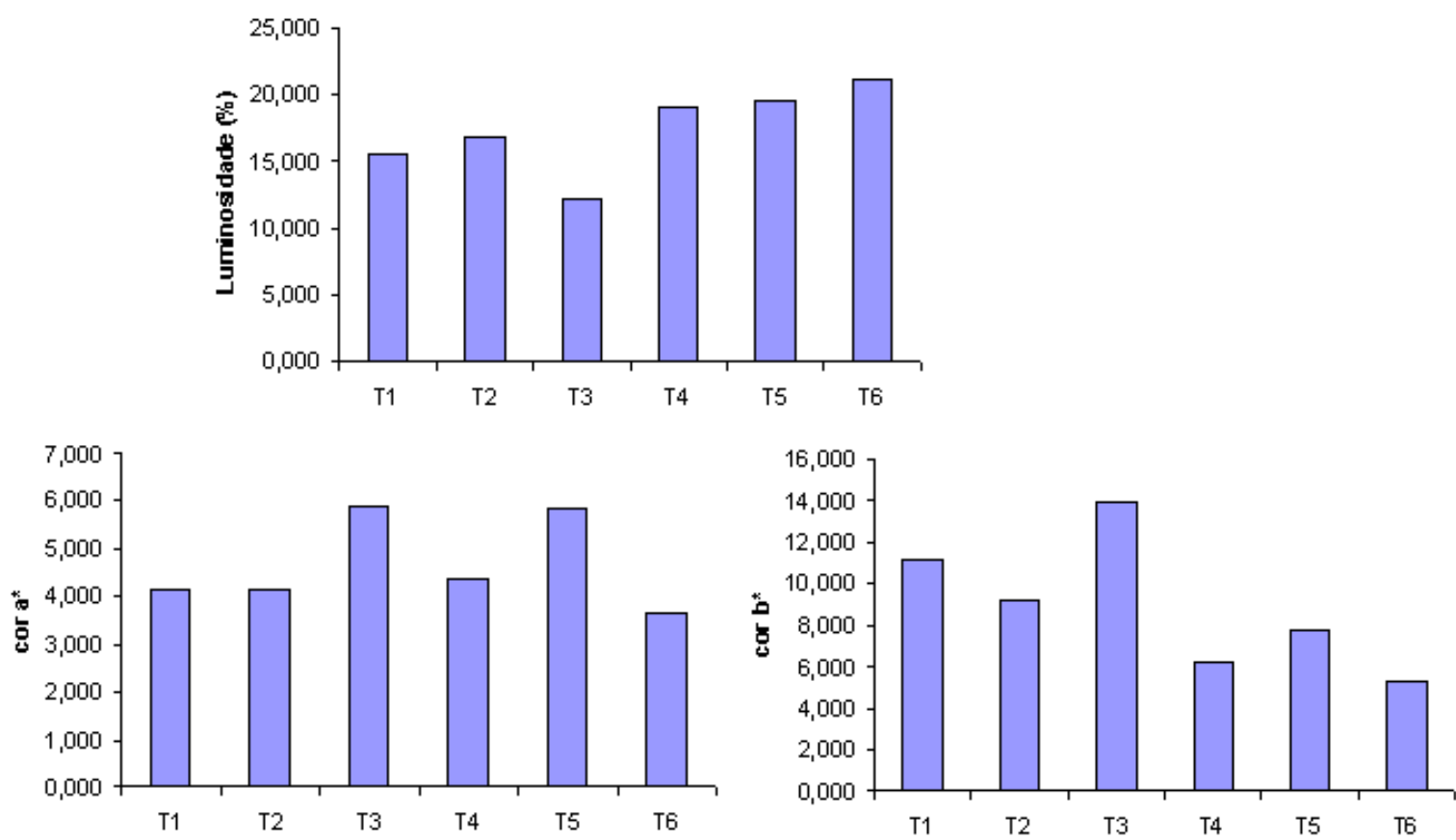

Figura 1 - Valores de luminosidade (L), intensidade de vermelho (a*) e intensidade de amarelo (b*) em função do tipo de tacho e matéria prima.

Para a luminosidade observou-se a diferença entre os tratamentos feitos com polpa e com suco. Na Figura 1, os tratamentos com suco apresentaram-se mais claro e pode justificar os valores mais elevados de luminosidade. Isso deve ter acontecido, devido ao fato do suco extraído ser mais límpido em relação a polpa, porque na prensagem para obter o suco, as frutas são esmagadas e não gera sólidos como ocorre na obtenção da polpa. O maior valor encontrado para luminosidade foi para o T6, com suco em tacho de inox.

Uma contribuição significativa na cor da geléia é dada pelo componente de cor b* (amarelo) que apresenta valores superiores a cor a* (vermelho). Todas as amostras tiveram predominância da cor amarela (b*) sobre a vermelha (a*), e pode-se observar que nas formulações feitas com matéria prima polpa, a intensidade da cor amarela foi mais expressiva em relação às formulações das geléias feitas com suco e isso pode ser observado na Figura 1, pois a polpa tem uma predominância de cor mais amarelada. 


\section{CONCLUSÕES}

A produção de geléia de acerola com a polpa é viável, pois apresentou um maior rendimento em relação ao suco e o seu processo de extração é mais simples. Em relação ao tacho, os melhores resultados foram para as geléias produzidas em tacho de alumínio. Para a avaliação energética os valores não diferiram entre si, mas os resultados estão de acordo com a literatura.

\section{AGRADECIMENTOS}

À Fundação de Apoio a Pesquisa no Estado de São Paulo (FAPESP).

\section{REFERÊNCIAS}

ASENJO, C.F. Acerola. In: NAGY, S.; SHAW, P.E. Tropical and subtropical fruit composition, properties and uses. Westport: AVI, 1980 p.341-74.

ASSIS, M. M. M. et al. Processamento e estabilidade de geléia de caju. Revista Ciência Agronômica, Ceará, v.38, n.1, p.46-51, 2007.

BRASIL. Ministério da Saúde. Agência Nacional de Vigilância Sanitária. Métodos físico-químicos para Análises de Alimentos. 4.ed. Brasília: Ministério da Saúde, 2005. 1018p. (Serie A. Normas e Manuais técnicos).

BRASIL. Ministério da Saúde. Secretaria de Vigilância Sanitária. Aprova Normas Técnicas Especiais do Estado de São Paulo, relativas a alimentos e bebidas. Resolução da Comissão Nacional de Normas e Padrões para Alimentos - CNNPA n. 12, de 24 de julho de 1978.

BRASIL. Ministério da Saúde. Agência Nacional de Vigilância Sanitária. Aprova o regulamento técnico sobre rotulagem nutricional de alimentos embalados, tornando obrigatória a rotulagem nutricional. Resolução RDC n 360, de 23 de dezembro de 2003. Diário Oficial da União, Brasília, DF, 26 de dezembro 2003. Disponível em:

<http://e-legis.anvisa.gov.br/leisref/public/showAct.php?id=9059\&word=>. Acesso em: 12 jun 2010. 
BRUNINI, M.A. et al. Caracterização física e química de acerolas provenientes de diferentes regiões de cultivo. Revista Brasileira de Fruticultura, Jaboticabal, v. 26, n. 3, p. 486-489, 2004.

CHAVES, M.C.V.; GOUVEIA, J.P.G.; et al. Caracterização físico-química do suco da acerola. Revista de Biologia e Ciências da Terra. Campina Grande,v.4, n 2, p.1-10, 2004.

CHITARRA, M.I.F.; CHITARRA, A.B. Pós-colheita de frutos e hortaliças: fisiologia e manuseio. Lavras: Ed UFLA, 785 p.2005

COOPERATIVA CENTRAL DOS PRODUTORES DE AÇÚCAR E ÁLCOOL DO ESTADO DE SÃO PAULO (COPERSUCAR). Amostragem e análise da cana-de-açúcar. Piracicaba, 1980.

DESROSIER, N. W. The technology of food preservation. Westport: AVI, 1963. 405p.

GOMES, F. P. Curso de estatística experimental. 14. ed. Piracicaba: Nobel, 2000. 477 p.

GOMES, J.E.; PERECIN, D.; MARTINS, A.B.G. et al. Análise de agrupamentos e de componentes principais no processo seletivo em genótipos de aceroleira (Malpighia emarginata D.C.). Revista Brasileira de Fruticultura, Jaboticabal, v.22, n.1, p.36-39, 2000.

GONZAGA NETO, L.; SOARES, J. M. Acerola para exportação:aspectos técnicos da produção. Brasília: EMBRAPA, SPI, 1994. 43 p.

JACKIX, M. H. Doces, geléias e frutas em caldas: (teórico e prático). Campinas, SP: Ed. da UNICAMP; São Paulo: Icone, 1988. 172p.

JUNQUEIRA, K. P.; PIO, R. ; VALE, M. R. ; RAMOS, J. D. Cultura da Aceroleira. Lavras - MG: Ufla, 2002 (Boletim de Extensão).

LIMA, V.L.A.G.; MUSSER, R.S.; LEMOS, M.A. et al. Análise conjunta das características físicoquímicas de acerola (Malpighia emarginata D.C.) do banco ativo de germoplasma em Pernambuco. In: CONGRESSO BRASILEIRO DE FRUTICULTURA, 17., 2002a, Belém, Anais... Belém: SBF, 2002. CD-ROM. 
MAPA. Ministério da Agricultura, Pecuária e Abastecimento. Manual de Métodos de Analises de Bebidas e Vinagre. Acesso em 11/02/2008. Disponível em

http://www.agricultura.gov.br/portal/page?_pageid=33,1041355\&_dad=portal\&_schema=PORTAL.

MCARDLE, W. D.; KATCH, F.I.; KATCH,V. L. Fisiologia do exercício-energia,nutrição e desempenho humano. 3. ed. Rio de Janeiro; Guanabara Koogan. p. 195-197/450-457, 1992.

MÉLO, E.A.; LIMA, V.L.A.G.; NASCIMENTO, P.P.Formulação e avaliação físico-química e sensorial de geléia mista de pitanga PITANGA (Eugenia uniflora L.) e acerola (Malpighia sp) . B.CEPPA, Curitiba, v. 17, n. 1, p. 33-44, jan./jun.1999

MIGUEL, A.C.A. et al. Aproveitamento agroindustrial de resíduos sólidos provenientes do melão minimamente processado. Ciência e Tecnologia de Alimentos, Campinas, v. 28, n.3, p. 733-737, jul.-set. 2008.

MOREIRA, M. R. et al. Avaliação de açúcares redutores e não redutores em geléias de morango comerciais. In: SIMPÓSIO LATINO AMERICANO DE CIÊNCIA DE ALIMENTOS, 2005, Campinas. Anais... Campinas: SBCTA, 2005. 1CD ROM.

MUSTARD, M.J. The ascorbic acid content of some Malpighia fruit and jellies. Science, v. 104, p. 230231, 1946.

NEGRETE, V. Desenvolvimento de processo a vácuo para geléia de acerola e acompanhamento de vida de prateleira. 2001. 91p. Dissertação (Mestrado em Tecnologia de Alimentos) - Faculdade de Engenharia de Alimentos, Universidade Estadual de Campinas, Campinas, 2001.

PAIVA, J.R.; ALVES, R.E.; SANTOS, F.J.S. et al. Desempenho de clones de acerola no Estado do Ceará. In: CONGRESSO BRASILEIRO DE FRUTICULTURA, 17, 2002, Belém, Anais... Belém: SBF, 2002. CD-ROM.

QUINTAES, K.D., AMAYA-FARFAN, J., TOMAZINI, F.M., MORGANO, M.A., MANTOVANI, D.M.B. Migração de minerais de panelas brasileiras de aço inoxidável. Ciência e Tecnologia de Alimentos, Campinas, v. 24, n.3, p. 397-402, jul.-set. 2004. 
SERVIÇO BRASILEIRO DE RESPOSTAS TECNICAS (SBRT). Panelas para fabricação de doces caseiros. Belo Horizonte: CETEC, 2007. Disponível em

http://www.sbrtv1.ibict.br/upload/sbrt7000.html?PHPSESSID=6aa56910df57f5c60f1bee9de0deeaf0. Acesso em 08 de agosto de 2009.

SCHOLTZ, M.B.S.; STENZEL, N.M. Características fisioquímicas de frutos de acerola (Malpighia spp),cultivados no Paraná. In: CONGRESSO BRASILEIRO DE FRUTICULTURA, 14., 1996, CuritibaPR. Resumos... Londrina: IAPAR/SBF,1996. P.43.

SEMENSATO, L.R.; PEREIRA, A.S. Características de frutos de genótipos de aceroleira cultivados sob elevada altitude. Pesq. agropec. bras., Brasília, v.35, n.12, p.2529-2536, dez. 2000.

SILVA, D. J. Análise de alimentos: métodos químicos e biológicos. 2. ed. Viçosa, MG: Universidade Federal de Viçosa, 1990. 165 p.

SIMÃO, S. Manual de fruticultura. São Paulo: Agronômica Ceres, 1971. 530p.

SOLER, M.P. Industrialização de geléias. Campinas: ITAL, 1991b. 205 p. ( Manual técnico, n. 8). 